\title{
Technological Extension Networks and Regional Development: A Case Study In Brazil
}

\author{
Heitor Soares Mendes ${ }^{1^{*}}$, Marta Lucia Azevedo Ferreira ${ }^{1}$, Lia Hasenclever ${ }^{2}$, \\ Carlos Alberto Marques Teixeira ${ }^{3}$
}

\begin{abstract}
This paper outlines the performance of the recent policies to strengthen the Brazilian productive structure and to support the country's innovation. The method selected for the analysis is the case study. Based on bibliographic, documental, and empirical evidences, the objective of the present study is to investigate the effectiveness of the Brazilian Technology System (SIBRATEC), founded in 2007. The effectiveness of this system will be assessed through an outline of the institutional arrangement of the Technological Extension Network in Rio de Janeiro (SIBRATEC-ET Rede RJ) which supports competitiveness of micro, small and medium industrial enterprises (MPMEs) in the state of Rio de Janeiro. Results indicate that the institutional aspects of the arrangement do not contribute to facilitate the support to enterprises. The levels of efficiency and efficacy achieved with the use of the available technical-administrative state capabilities have failed to correspond to the expectation of providing consistent support to the state's industrial base. However, the instruments SIBRATEC-ET Rede RJ uses to assist local MPMEs are flexible and designed aiming to adjust to the identified enterprises' demands, which evidences great adherence in the provision of support to improve the performance and the capacities of enterprises, in order to reach the level of key-technologies.
\end{abstract}

Keywords: Public Policy; Science, Technology and Innovation Policy; Brazilian Technology System; Technological Extension Networks; Regional Development.

Submitted: Aug 31 $1^{\text {st }}, 2018 /$ Approved: Oct $25^{\text {th }}, 2019$

\section{Introduction}

After a long period without elaborating explicit industrial and technologic policies, the Brazilian government decided to support the development of the national innovation system in the $21^{\text {st }}$ century, following the trend of other developing countries (Salami and Soltanzadeh, 2012; Chaurasia and Bhikajee, 2016). The Growth Acceleration Program $\left(\mathrm{PAC}^{1}\right.$ ) was founded in 2007, and was articulated with the Action Plan of Science, Technology and Innovation for National Development during 2007-2010 (PACTI 2007-2010). In this context, in the same year the Brazilian Technology System (SIBRATEC) was implanted. This system aims to support the technological and innovative development of Brazilian enterprises through the installation of three types of network (innovation centers, technological services, and technological extension) that had their own Technical Committee, which articulated with one another and were coordinated by a centralized management committee.

The network structure of the SIBRATEC is organized in sectors or regions so as to articulate the Science and Technology Institutions' (ICTs) infrastructure, which fosters the service provision according to the demands of Micro, Small, and Medium-sized Enterprises (MPMEs) from the industrial and service sectors, with funds granted by the National Fund for Scientific and Technologic Development (FNDCT). In the present paper we intend to investigate, on the supply side, the provision of institutional support and the effectiveness of the new model of technological extension policy (SIBRATEC-ET) in the regional context, that is, in the state of Rio de Janeiro (ERJ), named the Technological Extension Network of Rio de Janeiro (SIBRATECET Rede RJ). On the demand side, we focus on the current demand for technological and organizational capability of the industrial MPMEs located in the West Zone (ZO) of the state's capital, an important area of industrial activity in the state of Rio de Janeiro (ERJ).

One of the core aspects of technological extension - previously named industrial extension - is the support to the modernization of enterprises through the diffusion of existing technologies that are not used in groups of smaller enterprises, because of the characteristics of the latter. Technologies used to upgrade and enhance the development of both domestic products and processes that need to have compliance with international patterns for exportation have come across continuity problems of the existing extension programs (Madeira, 2009).

Innovation is a fundamental element of economic dynamism; it is the perspective that guides the analysis of the current technological extension model, considering the regional arrangements and their capacity to provide consistent support to MPMEs in terms of production modernization, namely, improvement of technological and organizational capabilities. Therefore, we intend to answer the following research question: is this model appropriate for providing support to the productive and innovative development of the MPMEs in the $\mathrm{ZO}$ ? In order to answer this question, the present paper is divided in six sections, besides its introduction. In section two, a brief literature review is presented regarding the aforementioned themes; in section three, the methodology used is displayed; in section four, the

${ }^{1}$ All abbreviations will be translated to English and their corresponding initials will be maintained in Portuguese.

1) Federal Center for Technological Education Celso Suckow da Fonseca (CEFET-RJ), Rio de Janeiro, Brazil.

2) Federal University of Rio de Janeiro, Institute of Economics (IE-UFRJ), Rio de Janeiro, Brazil.

3) National Institute of Technology (INT), Rio de Janeiro, Brazil.

${ }^{*}$ Corresponding author: heitor.mendes@cefet-rj.br 
implementation process of the SIBRATEC-ET Rede RJ is described; the demands of the metal-mechanical sector, with focus in the $\mathrm{ZO}$ are presented in section five, followed by the analysis and discussion of empirical evidence in section six; in section seven the conclusion of the paper is presented.

\section{Literature Review}

Both the State and institutions play a key role in economic development, since such development comprises structural changes, and the market itself is not the only nor the most efficient organization institution of the economic system (Fiani, 2011; Chang, 2002, 2003, 2011; Evans, 1995, 2010, 2011; Mazzucato, 2011). It is to increase coordination of economic activities and to reduce waste that societies create rules or institutions that both restrict and stimulate collective actions. The State's active intervention through specific policies to stimulate S\&T, industrial development, competition and trade is achieved by different means, as the results obtained in the institutional arrangements that involve interaction of the State with the market and the society, that have increased the interest of policy makers.

It is worth mentioning that the interdependence among the technological, institutional and ideological dimensions of these changes was pointed out by Kuznets (1973) when referring to the model of economic growth inaugurated in the Industrial Revolution. Gerschenkron (1962) provided seminal contribution to the understanding of the cathing up process, as he highlighted the role of institutions, of the intellectual climate, and of the ideologies in the accelerated industrialization process experienced in Germany and in Russia during the $19^{\text {th }}$ and the beginning of the $20^{\text {th }}$ centuries. Schumpeter (1961, 1976), in turn, emphasized the impact of technological innovations, of entrepreneurship, and of competition on the economy, exposing the unstable nature of the capitalist system. The author also explained the role of incremental changes in economic growth, and how redesigning processes affects development; the latter being a result of a "creative destruction" process.

Institutions certainly introduce regularities in the economic environment, in contrast with the inscreasingly rapid pace in which technologies are created and diffused. There is an intense interaction among technological innovation, economic growth and institutions, which indicates that such concepts cannot be fully understood separately (North, 1990). Due to the uncertainty, dynamism and complexity that characterize the current economic environment, the States have been challenged to design development strategies and specific policies that consider international integration, and also consider and meet domestic demands. In this context, it is possible to observe the resuming of the discussions about the theories of development, while the institutional economy has drawn more and more attention.

Public policies can be characterized as a construct that derives from various variables, and is oriented by values, ideologies, among other aspects that are inseparable from the policy makers; aspects that stem from the social forces that are involved in the formation and effectiveness of the public policies, and to which the public policies are the balancing point. Chrispino (2016, p.19) claims that "Public Policies" is a meta-concept since it is characterized as an "intentional government action that aims to meet collective necessities". In Brazil, the PACTI 2007-2010 comprises various initiatives that meet these collective necessities, here understood as the actions that streghten S\&T and innovation, and that foster the national economic development. One of the most recent initiatives articulated in Brazil is the SIBRATEC system. It involves dimensions that will be analyzed under the institutional arrangements spectrum, which are responsible for the sustainability of the implementation of public policies (Gomide and Pires, 2014). We intend to verify if the set of rules and regulations that are present in the arrangement of one of SIBRATEC's programs - the technological extension program in one of the country's state - permits the coordination of the operation of economic activities that are carried out with the policy's targeted public. In this sense, we also consider the relevant role the State and formal rules play in the coordination of the operation of economic activities among independent agents that have divergent interests and heterogeneous knowledge (Chang, 2002, 2003, 2011; Evans, 1995, 2010, 2011; Mazzucato, 2011).

Therefore, it is hoped that the SIBRATEC-ET network as an institutional arrangement presents regularity of action over time, with predictable and agreed changes that promote the absence of conflict, since its managing function will be defined and executed in a viable manner (Hodgson, 1988; Langlois, 1986; Rutherford, 1994, 2001). As a public policy, it is hoped that the architecture and the strategies of the implementation of such an arrangement are materialized in a set of intentional actions that correspond satisfactorily to the input - the state capacities made available aiming their successful completion. In this dynamic process, the program may also be evaluated through the analysis of technical-administrative capacities, and through the basic public policy indicators: efficiency, efficacy and effectiveness (Arretche, 1999; Chrispino, 2016).

Thus, taking into account the goals set by PACTI as a public policy, it is important to understand the relevance of supporting the MPMEs' technological and organizational capacities for the national development. The latest United Nation Conference for Trade and Development Report (UNCTAD, 2016) emphasizes the importance of the transformation industry in all countries' economic growth and development, especially in developing countries. Moreover, it is known that there are barriers to the access to the technological information frontier and even to the access of the already well-established production and business management technologies, which are widely disseminated in big companies operating in Brazil, but not used by MPMEs.

Rovere et al. (2014) and Mendes and Hasenclever (2015) explore the barriers that hinder the catching-up process of this type of national enterprise. It is important that MPMEs cease to represent the 'weak link' in potential productive chains in the national economic scenario, especially in the industrial base of the ERJ. If the technological and organizational deficiencies these companies present persist, the outcomes will consist in weak economic results in terms of value creation in the industry, in spite of the quantitative 
importance these companies have when it comes to income and employment generation in relative terms ${ }^{2}$. However, the elevation of the technologic pattern is not a spontaneous, available and attainable process for MPMEs; the provision of support to the capacitation of these enterprises is indispensable.

Studies confirm the lack of the much-needed support to MPMEs, which if properly provided could result in the possibility of reaching higher technologic capacity patterns (Nogueira, 2017; OECD, 1997). Indeed, such enterprises need to migrate from lower standards (operation with low or minimum technological capacities), to reach the level of technological capacity currently followed by the competition; a level that is present in their routines, and that will enable them to develop their capabilities to the point they are able to be included in the group of enterprises that have endogenous research and development resources, which, in turn, will enable them to invest on continuous innovation to reach and to stay in the technological frontier.

\section{Methodology}

This paper presents the results of a research of qualitative and empirical nature with descriptive purpose. The selected method was the case study ${ }^{3}$ that is compatible with the deep analysis of contemporary and complex phenomena. This method involves the collection of multiple sources of evidence, also involving the chaining of evidence towards convergence, based on previously developed theoretical foundations (Yin, 2014). Therefore, we use bibliographic, documental, and observational sources, besides the collection of information through the application of a semi-structured questionnaire to experts and managers of MPMEs working in the metal-mechanical sector in the $\mathrm{ZO}$ of the ERJ. To the evidence are also added semi-structured interviews conducted personally with experts and managers of the SIBRATECET Rede RJ, carried out with the purpose of understanding the opinions and perceptions of interviewees.

Based on the technological and organizational demands identified in the studied industries, and on the collected information about the operation of the institutional arrangement, we intend to verify the effectiveness of the support the arrangement provides to the competitiveness of the MPMEs in the region. The method of assessment of the provision of support vis-à-vis demand is the analysis of adherence among the instruments of support provided by the extension program. This analysis was carried out through the elaboration of a correlation matrix that included technological and organizational demands of MPMEs, and the SIBRATEC-ET Rede RJ support supply. The analysis of the institutional arrangement is based on the identification of objectives and results achieved with the implementation of the arrangement in the ERJ in the period 2009-2016. All activities carried out during this period are considered, as well as the use of State technical-administrative capabilities. The parameters for measuring the arrangement's performance included: the efficacy of policies, with the use of a degree of alignment with the expected results; the efficiency of the program, including a benefit-cost evaluation; the effectiveness related to citizen degree of satisfaction or related to the assistance and its scope considering the targeted beneficiaries. Other aspects included in the evaluation of the arrangement regard the operation of coordination mechanisms, and to the identified monitoring strategies.

The selected empirical research object is the metal-mechanical sector of the ERJ, represented by a subgroup, the agglomeration of enterprises of this industrial area, located in the west zone of the city of Rio de Janeiro (MRJ). The metal-mechanical sector involves an elevated number of microeconomic agents disseminated nationally. As the identification of such agents is not viable considering their elevated number, we selected a sectoral agglomeration that is economically relevant in the regional level. The list of the enterprises that make up the base selected for a field research was elaborated based on the 2007/2008 records of the Federation of Industries of Rio de Janeiro (FIRJAN) - updated in 2014.

The MPMEs samples were organized considering two selection criteria: the first was the sectorial criterion of the companies' operation, using the National Classification of Economic Activities (CNAE) (IBGE, 2014), with enterprises that are in the following CNAE 2.0 classification: section C, divisions 24 (Manufacture of Basic Metals), 25 (Manufacture of Fabricated Metal Products, except Machinery and Equipment), 28 (Manufacture of Machinery and Equipment n.e.c.). The second selection criterion was the size of the enterprises, defined here by the number of employees, considering the methodologic orientation provided by the Brazilian Support Service to Micro and Small Enterprises (SEBRAE), which makes the following classification: microenterprise - up to 19 employees; small enterprise - 20 to 99 employees; medium-sized enterprise - 100 to 499 employees. The intentional sampling includes 59 enterprises of the sector and 23 interviews, which represents $39 \%$ of the sampling collected between August of 2015 and January of 2016. Interviews lasted about $40 \mathrm{mi}-$ nutes each.

\section{The Supply Side: SIBRATEC-ET Rede RJ}

Table 1 presents the aspects concerning the implantation of SIBRATEC, and the characteristics of its technological extension network are displayed. The operation of the arrangement in the ERJ had specificities in each modality of assistance, but, mainly, it followed a pattern.

\footnotetext{
${ }^{2}$ In the industrial sector, the MPMEs represent $98.8 \%$ of the total, but generate only about $24 \%$ of the gross value of industrial production (VBPI), and $22 \%$ of the value added (Rovere et al., 2014).

${ }^{3}$ Further details on the questionnaire and methodology used available in Mendes (2016).
} 
Table 1. SIBRATEC and SIBRATEC-ET.

Origin: Science, Technology and Innovation Action Plan for National Development (PACTI 2007-2010) - MCTI. Launched in 2007.

Framework: Structuring axis II. Strategic Priority: the promotion of technological innovation at enterprises. Objective: intensification of the actions to promote innovation and technology at enterprises.

SIBRATEC: part of line of action number 5 (Technology for Enterprise Innovation). Legal framework of creation: Decreet number 6.259/2007. Systemic model, structured in three networks: Innovation Centers; Technological Extension; and Technological Services. Governance: each SIBRATEC network has its own managing technical committee; however, their actions are interrelated, and have centralized coordination from the system, performed by a management committee.

Objective: the structuring of a national technology system, through the creation of networks, entities and orgains that promote innovation and provide technological services for enterprises, aiming to have nationwide coverage. In Article number 1, subsection II of Decreet number 6.259/2007, the extension of scope is displayed as one of the SIBRATEC goals.

SIBRATEC-ET: one of the three networks structured by SIBRATEC. It concerns the technological extension of the system.

Technological Extension Program: Structured in regional institutional arrangements; Proactive character, prospection of enterprises to receive direct assistance; the program has a permanent source of financing: the National Fund for Scientific and Technologic Development - FNDCT; state programs were structured by arrangements that originally aimed to join successful extension products, which in turn would join actors in a local logic of development, with local actors, besides FINEP -the institution that manages the FNDCT-, and other entities that would provide corporate support, such as SEBRAE. The implementation of SIBRATEC-ET Rede RJ happened in 2009, and its assistance service started in 2010 .

Institutional Arrangement: technical coordination performed by the National Technology Institute (INT); The Technology and Innovation Network of Rio de Janeiro (REDETEC), worked with the articulation with the ICTs and as the administrative and financial managing institution; the Brazilian Support Service to Micro and Small Enterprises in Rio de Janeiro (SEBRAE-RJ), worked with the provision of support to the articulation with micro and small enterprises (MPE) in the state, and also financing 10\% of the arrangement; the Foundation for Research Support in Rio de Janeiro (FAPERJ), also financed 10\% of the arrangement; the Studies and Project Financer (FINEP) provided the biggest amount of funds to the arrangement (70\%). The assisted enterprises had 10\% of participation in the financing of the arrangement.

Source: Adapted from MCTI (2013a); Mendes (2016); Mendes and Hasenclever (2015); and Mendes et al. (2017)

Firstly, the technological extentionists prospected enterprises for assistance, and presented the modalities of support to the productive development to them, as well as the conditions to take part in the program, emphasizing the low financial participation of the MPMEs. Secondly, diagnosis of each situation was carried out, which could be either be performed by the extentionist, or, in case the extentionist lacked the expertise, the diagnosis was delegated to a group of experts.

Table 2 presents the distribution of services by modalities used by the arrangement in the ERJ, as well as it summarizes the goals set for each modality of assistance. According to the arrangement's final report (INT, 2016), the MPMEs were selected in order to strengthen the local productive systems in the ERJ, considering both the definition provided by the Secretariat of Economic Development, Energy, Industry and Services of the state of Rio de Janeiro (SEDEIS), as well as the local economic peculiarities.
Table 2. Amount of Estimated and Completed Assistance of SIBRATEC-ET Rede RJ (Aug 2009/Feb 2016).

\begin{tabular}{lcc}
\hline Modalities of Assistance & $\begin{array}{c}\text { Goals } \\
\text { Set }\end{array}$ & $\begin{array}{c}\text { Total of Answered } \\
\text { Calls }\end{array}$ \\
\hline $\begin{array}{l}\text { Technological compliance via mobile } \\
\text { unit - foods and beverages }\end{array}$ & 50 & 50 \\
$\begin{array}{l}\text { Technological compliance of pro- } \\
\text { ducts for the external market }\end{array}$ & 35 & 35 \\
$\begin{array}{l}\text { Technological compliance of pro- } \\
\text { ducts for the domestic market }\end{array}$ & 35 & 36 \\
$\begin{array}{l}\text { Technological compliance via pro- } \\
\text { duction management }\end{array}$ & 09 & 09 \\
$\begin{array}{l}\text { Technological compliance via cleaner } \\
\text { technologies }\end{array}$ & 14 & 14 \\
Total & 143 & 144 \\
\hline
\end{tabular}

Source: Adapted from Mendes et al. (2017); INT (2016). 
The various modalities of the SIBRATEC-ET assistance followed an average duration pattern: Technological compliance via mobile unit foods and beverages (four months); Technological compliance of products for the domestic market (one year); Technological compliance of products for the external market (one year and six months); Technological compliance via production management (five months); Technological compliance via cleaner Technology (eight months) (INT, 2016).

Originally, the agreement made for the arrangement estimated two modalities of assistance and the following targets: 'Technological compliance of products for the external market' - the goal set was of 140 calls; and 'Mobile Unit - Foods and Beverages' - 60 calls. The original perspective of the arrangement's scope was expanded throughout the term of the agreement (including renegotiations of terms), and new modalities of assistance were incorporated, which in turn created the need for the reconfiguration of general goals, with the inauguration of a new scope of assistance to be provided by the arrangement in the ERJ.

During the term of the agreement, 264 calls were answered and classified in the arrangement as 'closed' and 'suspended. Classified as 'closed' were all of the cases that had their assistance completed with the solicitants. 'Suspended' is the term that includes all of the other conditions, according to the status of the assistance by the end of the agreement's term; for instance: 'in progress', 'negotiations in progress', 'pending', 'suspended', 'expired', and 'invalid'.

Regarding the size of companies, 45 micro (42\%) and 62 small-sized enterprises (58\%) were assisted, totalizing 107 enterprises. In terms of modalities of assistance, extension services were provided through all five modalities. The assistance provided can be discriminated by size. Table 3 presents these results, taking into account only the cases considered completed.

There seems to be an inconsistency in these data, since SIBRATEC-ET Rede RJ assisted only 107 enterprises in the term of the agreement, and the total of answered calls is of 133 enterprises. The explanation is that some enterprises have had more than one call answered. In addition, it is also noticeable in Table 3 the absence of provision of support to medium-sized enterprises during the term of the agreement in the ERJ.

Table 3. Estratification by Enterprise Size and by Modalities of Assistance of SIBRATEC-ET Rede RJ.

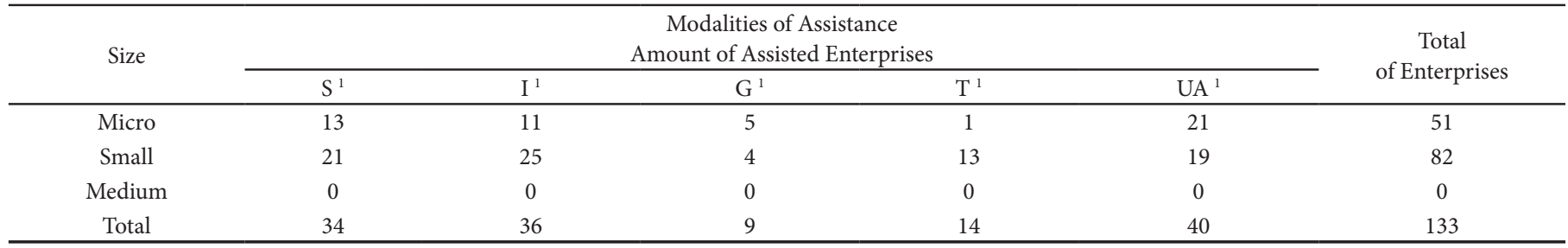

Note 1- Codification: S - External market; I - Internal market; G - Production management; T - Cleaner technologies; UA - Mobile units. Source: Adapted from Mendes et al. (2017); INT (2016).

Table 4 presents a qualitative synthesis of the institutional arrangement's implementation in the ERJ. This one indicates that the results obtained with the implementation of the SIBRATEC-ET Rede RJ extension program in the ERJ were not satisfactory. The program already presented poor results in the 'Management Report
- SIBRATEC Program 2013' (MCTI, 2013b), and based on the final observations made in the final report elaborated by the coordination agent (INT, 2016), it is possible to notice the general challenges and difficulties all extension programs came across; notably, governance difficulties.

Table 4. SIBRATEC-ET Rede RJ - Qualitative Results Obtained in the Implementation of the Program.

\footnotetext{
Characterization of the SIBRATEC-ET Rede RJ Arrangement

1. Demand oriented program in terms capacity of assistance; it had initial coverage of 10 enterprise calls per month

2. Five modalities of assistance were used in the SIBRATEC-ET Rede ERJ.

3. Modalities with specific characteristics, but with relatively open instruments of assistance, adjustable to the demands of the solicitants.

4. Low efficacy; the assistance was interrupted multiple times during the term of the arrangement in the ERJ.

5. There was the necessity to renegociate the agreement throughout the operation of the program. Adjustments were made even in the goals originally set and agreed on.

6. The support was not provided in the ZO of the MRJ, area selected for the study of the MPMEs' demand for technological capabilities.

7. The program was not formally publicized; the publicizing was carried out in an informal, non agreed manner, with the support of the INT at one point, through the elaboration of brochures.

8. The program did not achieve the original goals in the period estimated in the agreement. The number of calls answered was very small considering the time of operation of the program in the ERJ. Consequently, the program had low efficiency.

9. Conflicts have been identified in the operation of the extension instruments SIBRATEC-ET Rede RJ and SEBRAETEC ${ }^{1}$, since there were many similarities in both, and there was potencial competition in the ERJ. A governance agreement was necessary in SIBRATEC-ET for the activities of both instruments to be as complementary as possible in their operation, so as to optimize the use of resources, and to generate less conflict and less competing actions. This agreement was partially effective, but not for long. Nonetheless, the SIBRATEC-ET Rede RJ lost intensity in this process.
}

Note 1: The SEBRAETEC program is a SEBRAE National initiative reactivated in 2012, with ambicious goals. It is regionally operated by SEBRAE-RJ, an institution that takes part in the governance of the SIBRATEC-ET Rede RJ arrangement.

Source: Adapted from Mendes (2016) and Mendes et al. (2017); INT (2016).

ISSN: 0718-2724. (http://jotmi.org)

Journal of Technology Management \& Innovation ( ) Universidad Alberto Hurtado, Facultad de Economía y Negocios. 
The present research presents the identified following barriers to the implementation of the SIBRATEC-ET Rede RJ: the difficulties that result from the SIBRATEC-ET networks' governance organization, since it involves two levels of federative entities (federal and state) in the same arrangement; the different administrative/legal federal and regional requirements that hamper the transfer of funds from these two federal levels of government to the programs; the difficulties in the insertion of SIBRATEC-ET networks into other public or private initiatives that support micro, small-sized and medium-sized enterprises; the temporality, since the networks operate during specific previously agreed periods of time, and their management projects do not have prospects nor criteria for continuity; the lack of instruments to conduct periodic performance evaluations of the networks and their institutions.

It is possible to identify in the final report of the arrangement in the ERJ the cities ${ }^{4}$ where the assistance to support enterprises was more intense. Only three cities (out of 92) concentrated more than half of the assistance provided: Rio de Janeiro, that concentrated $24.2 \%$ of the answered calls, followed by Nova Friburgo that concentrated $17.9 \%$, and Petrópolis with $11 \%$ of the total of calls answered in the ERJ. The initial criterion for the area selection was the export potential the enterprises presented. A total of 190 enterprises have been diagnosed in the ERJ. Diagnoses were performed in $42.4 \%$ of the cities in the ERJ during the term of the SIBRATEC-ET Rede RJ agreement (Aug 2009 - Feb 2016). The following sectors have had 'closed' calls: Foods and Beverages (49\%); Fashion (26\%); Transformation Industry (furniture and plastic) (14\%); Metal-Mechanical (10\%); and Civil Construction (1\%). Out of the 190 diagnosed enterprises, 107 have had adjustments completed and 'closed' calls in the ERJ, which represents $56.3 \%$ of diagnosed MPMEs.

\section{The demand side: The Metal-Mechanical sector of the West Zone of the city of Rio de Janeiro}

In this section we present a synthesis of the partial results obtained from a survey that identified MPMEs' capacities and demands for technological and organizational capabilities in the metal-mechanical sector of the ZO of the MRJ, elaborated by Mendes (2016). Considering the number of participant enterprises, in relation to the total of enterprises listed in the $\mathrm{ZO}$ separated by main economic activity, we verified that $29 \%$ of the enterprises listed under the 'basic metals' division (CNAE 2.0 code 24) have taken direct part in the survey; in the 'metal products' division, (CNAE 2.0 code 25) 38\%; and in the 'machinery and equipment' division (CNAE 2.0 code 28 ), 46\% participated directly in the survey.

Table 5 summarizes part of the results obtained, describing the situation of the metal-mechanical enterprises located in the ZO. The aspects presented in the chart relate to the identification of the MPMEs' demands for technological and organizational capabilities.

Table 5. Case Study: Metal-Mechanical MPMEs - ZO of the MRJ - Summary of the Interviews' Results.

\footnotetext{
1. Few actions aimed at seeking improvements externally.

2. Principal access to new technologies: acquisition of machinery and equipment.

3. Fragility in Basic Industrial Technology (TIB).

4. Human resources with low technical qualification in TIB.

5. Organizational demand: under $50 \%$ of the MPMEs use organizational management systems.

6. Unfamiliarity with the SIBRATEC system.

7. Where would they ask for support?

-FIRJAN: $65 \%$

-UFRJ: $52 \%$

-SENAI: $65 \%$

-SEBRAE: $56 \%$

8. Strategic business partnerships: only one enterprise has confirmed to have strategic business partners.
}

9. Financial support: where would they ask for it? Banco do Brasil: $61 \%$

The Brazilian Development Bank (BNDES): 48\%

10. Demand for qualified professionals:

Technicians (high school level): $83 \%$

Engineers: $44 \%$

11. Benchmarking:

Never procured from suppliers: $73.9 \%$

Never procured from current or future clients/markets: $69.6 \%$

12. Managers' behavioral characteristics:

a. Pessimistic when it comes to governament support;

b. Unfamiliar with local enterprises;

c. Fail to establish local inter-enterprise relationships.

Source: Adapted from Mendes (2016)

Regarding competitiveness and enterprises' growth, results indicate that, currently, the five main criteria of business competition preservation in decrescent order, according to the interviewed group of metal-mechanical enterprises, are: 'product quality', 'cost control', 'customer relationship management', 'access to new technologies', 'investment in human resources'.
Demands are presented under the name 'challenges' that enterprises come across. Three of these demands stand out for representing the needs that most of the interviewees have: the first persistent challenge for $82.6 \%$ of the interviewed enterprises is 'continuous market monitoring'; the second challenge pointed out by $73.9 \%$ of interviewed MPMEs is the demand for 'new technologies for the manufacturing

${ }^{4}$ City in this case refer to a municipality. 
of the enterprises' current products'. The third challenge mentioned by $65.2 \%$ of interviewees is the insertion of 'new management technologies to increase productivity'. Besides the three aforementioned needs, three other relative demands also stood out for $39 \%$ to $56 \%$ of the interviewed enterprises. These demands are worth highlighting because of their complementary character in relation to bigger demands; namely: 'new quality management technologies' (56.5\%), 'design improvement / product development' (43.5\%), and 'use of new materials' (39.1\%).

Regarding the institutional support, the majority of enterprises do not use nor would they use the support provided by all institutions and organizations listed. The SIBRATEC-ET institutional arrangement in the state of Rio de Janeiro was not solicited by any of the local interviewed enterprises. None of the enterprises mentioned the institutions of the SIBRATEC-ET arrangement, and only $13 \%$ of enterprises confirmed that they would use the arrangement's services to benefit from the provided technological and organizational development support. It is noticeable that there is great unfamiliarity with the SIBRATEC-ET network, whose main characteristic is the provision of support to the state's MPMEs. This scenario is not favorable considering the institutional mission of this program: meeting the technological and organizational demands of the national industry. In addition, this nationwide system has structured support that could perfectly meet the local enterprises' needs.

\section{Analysis and Discussion}

Considering the described structural aspects of the SIBRATEC-ET arrangement, it is possible to identify the complex character that inter-institutional interactions involve. Considering such complexity, it is necessary to perform an evaluation of the relevance of the proposals present in the studied public action (Gomide and Pires, 2014). The period of the agreement, including the extension of time, terminated in February of 2016. Based on the presented results regarding both the technological and organizational demands of MPMEs as well as the implementation of the SIBRATEC-ET Rede RJ program, it is possible to, critically evaluate this institutional arrangement.

The 'Management Report -SIBRATEC Program 2013' (MCTI, $2013 \mathrm{~b}$ ) indicates poor results of the extension network in the ERJ until that year. The results obtained in the state of Rio de Janeiro were the worst among all other programs in operation. Programs operating in the states of Minas Gerais and Paraná also presented weak results according to the report. By the end of the agreement's term, the results in the ERJ remained weak, even though a modest evolution was identified. Meanwhile, the other two states have presented significant evolution in their results. ${ }^{5}$

The scenario described by the responsibles for the arrangement already indicated little advancement and many barriers to the management and to the provision of effective support for the group of enterprises located in the ERJ (Mendes, 2016). Indeed, under the quantitative spectrum, and considering the results of the agreement presented in the present research, it is possible to see that the SIBRATEC-ET Rede RJ underperformed its operation. Results failed to achieve the goals originally set, which projected an average of annual assistance. Other difficulties in the implementation of the SIBRATEC-ET Rede RJ were identified: interruption of operation during one year and seven months; dependence on bids to find the consultation indispensable for its execution; discontinuation of assistance; lack of institutional security; faulty prospection of the enterprises' demands; lack of publicizing of the program; lack of funds destined for the program's publicizing.

Table 6 shows the arrangement's capacities comparing the normative character, present in the institutional design, to the effective operation of the arrangement in the state. As to the state capacities made available for the development of the state's enterprises, the conclusion is that there was weak capacity of providing effective support to the enterprises, even though there was flexibility in the modalities of assistance - due to the demand orientation of enterprises, and not due to rigid and standardized mechanisms. However, as it is possible to note, because enterprises had difficulties in the access of the program, the flexibility differential has mostly lost its relevance.

It is necessary to work on the failures identified in the present study, so that the regional arrangement achieves effectiveness. One of the failures identified regards the coordination. Many difficulties hindered the production of a continuous flow of assistance, because of many reasons: sometimes because of failures in the information flow among the arrangement's partners (in the 'supply $\mathrm{x}$ demand' relation, and in the back office support), sometimes because of the lack of flow of the funds which support the operation of the arrangement. Nonetheless, as mentioned in this study, coordination failures stem from a SIBRATEC systemic problem (MCTI, 2013b).

\footnotetext{
${ }^{5}$ This becomes evident when visiting the following website: $<$ https://www.dropbox.com/sh/40axojcm5dknebc/AABcVdS3pW274ZMZ6sklTyn5a?dl=0>. Last visited on April 25, 2017. The states of Minas Gerais and Paraná are mentioned as successful cases of the regional technological extension network.
} 
Table 6. SIBRATEC-ET - Barriers to the implementation in the ERJ (Capacities).

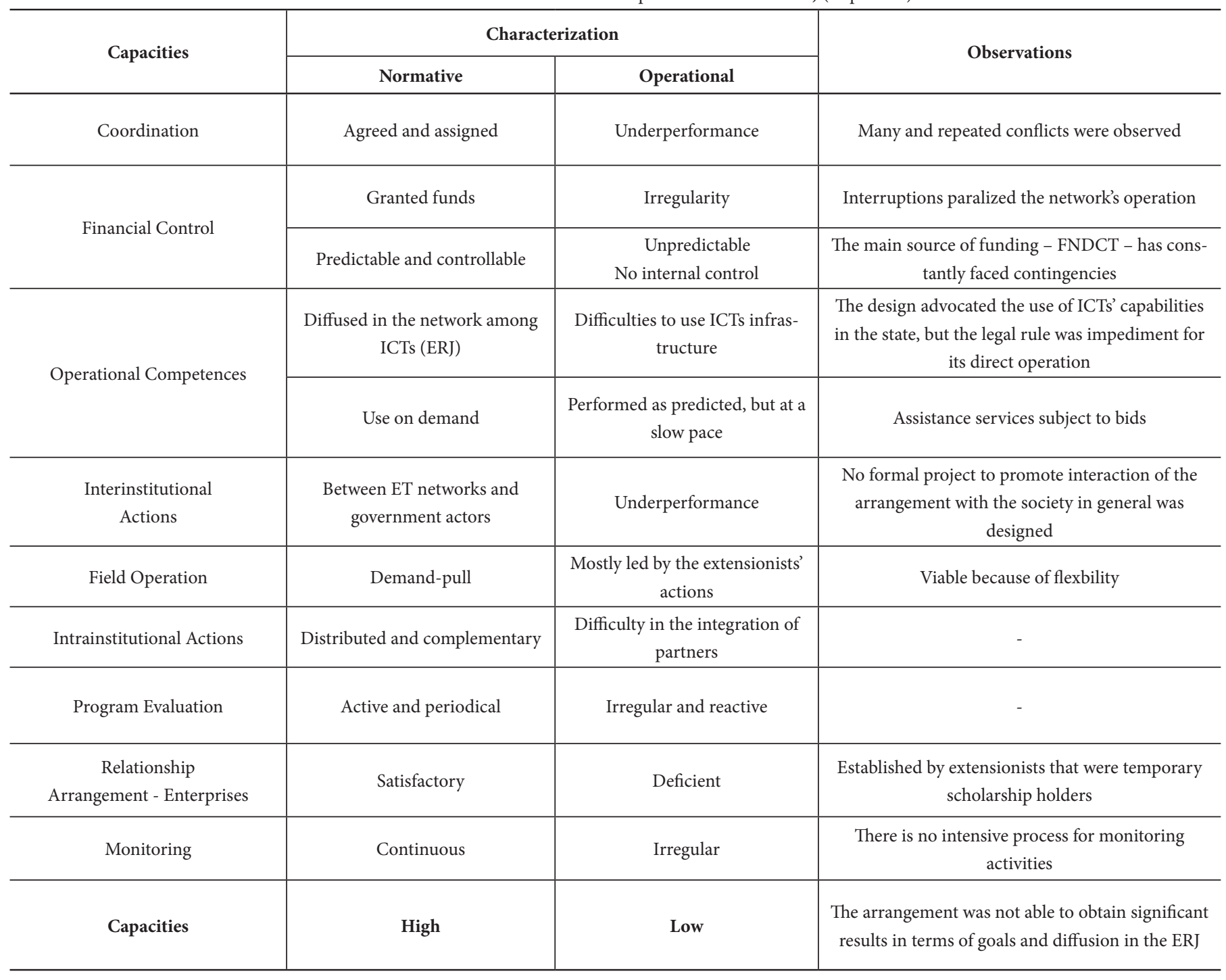

Source: Adapted from Mendes (2016) and Mendes et al. (2017).

Further problems were identified in the implementation of the arrangement, such as: complementarity versus competition between SIBRATEC-ET and SEBRAETEC, which has even caused misunderstanding among solicitants, since the names of the two programs are extremely similar. The agreement, terminated in 2016, does not have a certain future when it comes to continuity. Such uncertainty weakens even more the credibility of the system in the operation of government actions to support the MPMEs in the state of Rio de Janeiro.

Table 7 presents the correlation of the MPMEs' technological demands, and the adherence of the SIBRATEC-ET Rede RJ modalities of assistance made available for enterprises. Results indicate that $91 \%$ of the enterprises that took part in the research have at least one technological or organizational demand. All of these demands represent challenges for this group of MPMEs that hinder: the acquisition of the necessary capabilities to absorb technologies, the compliance of such technologies to make them proper for use, the diffusion of these new capacities among the technical team and the codifying of new knowledges in the corporate routines in order to better the performance of the business. All of these challenges if overcome would make the enterprises more competitive, considering the current competition conditions (Mendes, 2016).

In Table 7 the adherence of the modalities of assistance to the MPMEs' demands becomes evident. There are theoretical conditions regarding the metal-mechanical MPMEs' demands in product technology, process technology and management technology that are to be met by the SIBRATEC extension network. 
Table 7. Correlation - General Demands and the SIBRATEC-ET supply.

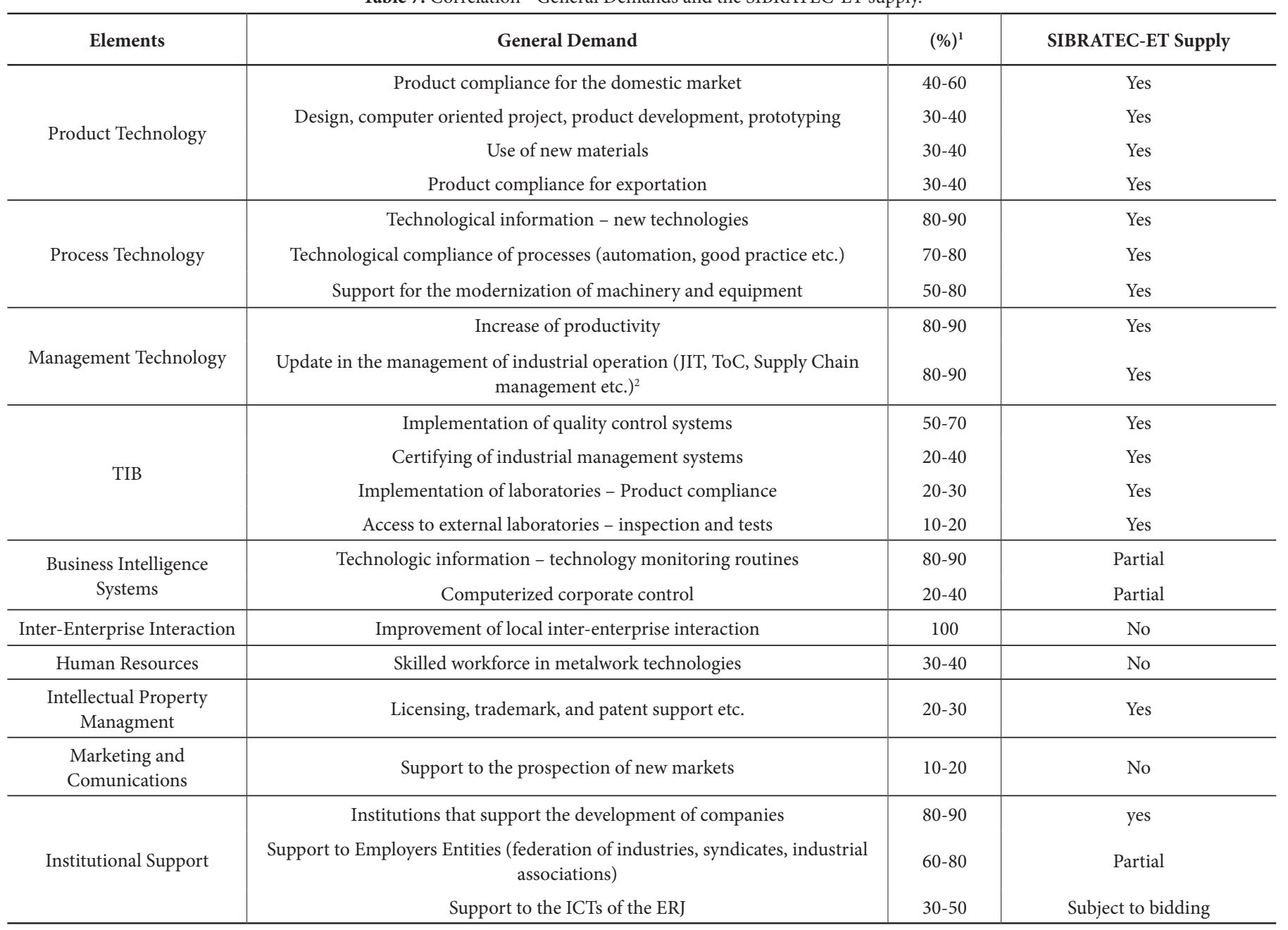

Note: 1- Relative amount estimated based on the demands of the interviewed companies.

Note: 2- JIT: Just in Time; ToC: Theory of Constraints.

Source: Adapted from Mendes (2016) and Mendes et al. (2017).

However, the implemented arrangement falls short on effectiveness in the state, in view of the multiple implementation obstacles, the regional network has come across in the ERJ. In this state, the assistance was not provided properly to the targeted enterprises in the institutional design: the industrial and technological services MPMEs located in the ERJ. There was poor efficiency and limited efficacy, once the goals met have had significantly poorer results when compared to the annual minimum that was projected for the operation with this kind of intervention.

\section{Conclusions}

Even though the instruments SIBRATEC-ET uses to operate are flexible and were designed aiming to ajust to the enterprises' demands, the institutional arrangement is not properly structured, once its weaknesses include coordination problems. The conduction rules were not well received by its members, and internal conflicts in the institutional partnership were identified. The present institutional aspects represent obstacles to the increase of competitiveness and of the development, instead of facilitating these processes - for example the case of the regularity expected from the institutional arrangement. In addition, the targeted levels of efficiency and efficacy were not achieved, and, even though some goals were achieved by the end of the agreement's term, this happened because terms were renegotiated, and the new terms agreed expired long after the original ones.

Therefore, the results presented indicate the lack of effectiveness of the SIBRATEC - technological extension network in the ERJ. The arrangement did not properly fulfill its institutional mission in the ERJ, which was to provide support to corporate development; the mission was not completed because the arrangement failed to have a satisfactory performance with the use of the technical-administrative capacities made available for its execution. This scenario generated inefficiency and inefficacy during the implementation of the system in the ERJ, which in turn frustrated the expectations of granting consistent industrial support. 
The demands of the metal-mechanical MPMEs located in the ZO indicated that the majority of this kind of enterprise have as a priority the development of products and processes that are more compatible with the market in which they operate, which requires continuous assistance in changes, and also assistance in the compliance of new requirements. In spite of the fact that part of the sector's enterprises belongs to low or medium-low technological intensity segments, the machinery and equipment segment is one of the most dynamic and innovative segments in the world, a pattern that is not followed in the country, nor in the studied enterprises. Prioritizing the elevation of technological and organizational capabilities of a group of enterprises (CNAE 28), for instance, is indication that the industry's innovation base is seeking expansion. In this case, the argument is that if a policy focuses on this division of economic activity, an important complement of this initiative (in the case studied the SIBRATEC system) would provide support to the productive chain of the segment through the insertion of technological extension mechanisms like the ones analyzed in the present paper.

The results presented must be used as base for the elaboration of a reform in the technological extension policy, for they suggest the redesigning of the composition of arrangements of this nature, which indicates the necessity of insertion of local leaders that will assist the targeted public of the policies in the regional level. Results also point out that the coordination of the arrangement will require, in the national level, reconfiguration of governance strategies.

The studied system also has important features that are worth mentioning, for they represent advancements in relation to previous adopted support systems. One of these advancements is the fact that the system's operation is led by the demand of enterprises for technological capability, and it is also worth highlighting that the system has presented flexibility to meet such demands, by making available for the MPMEs various modalities of assistance. An example of such flexibility is found in the present study, where the adherence of the supply to the support of the demand for key technology is evident in the studied metal-mechanical sector.

The SIBRATEC-ET network can also play an important role for one group of enterprises that has not been the focus of development public policies during the past decades: medium-sized industrial enterprises. The support for this group of enterprises has not been provided since the extinction of the Brazilian Center of Support to Small and Medium-sized Enterprises (CEBRAE); when this institution was transformed into SEBRAE, medium-sized enterprises ceased to receive support from the government. Therefore, the enhancement of the studied system would resume the provision of support to this group of industrial enterprises, with the reinsertion of such group in the agenda of public policies that support production development.

Micro and small-sized enterprises have the support of SEBRAE, an organization with great penetration in the country. Notwithstanding, medium-sized enterprises do not count on specific institutional support to foster their development. It is time to pay close attention to this group of national enterprises.
Considering the results identified for the technological extension network in the ERJ, the extinction of the network would be premature. Means of achieving its enhancement should be pursued instead, with the correction of the detected problems, especially considering that the program is regional in its arrangement implementation, however it is essentially nationwide. The program represents a potential element for making scale profit in the improvement of MPMEs' technological and organizational capacities, aiming to reduce the gap the country presents when compared to developed countries.

It is necessary to analyze of all the implemented technological extension networks, so as to point out the elements that must be the foundation of the arrangement's design and also the elements that create conflicts inside the arrangement, and, consequently, must be eliminated from the institutional arrangement's structure. Morevover, it is important to identify the successful results of each regional network that may be indicative of the path to be trailed. ${ }^{6}$

\section{References}

Arretche, M. T. S. (1999). Tendências no estudo sobre avaliação. In Rico, E. M. (Org.), Avaliação de políticas sociais: uma questão em debate (pp. 29-39). 2. ed. São Paulo: Cortez.

Chang, H. J. (2002). Kicking away the ladder: development strategy in historical perspective. London: Anthem Press.

Chang, H. J. (2003). Globalisation, economic development and the role of the state. London, New York: Zed Books.

Chang, H. J. (2011). Hamlet without the prince of Denmark: how development has disappeared from today's development discourse. In Khan, S. R. \& Christiansen, J. (Eds.), Towards new developmentalism: market as means rather than master (pp. 47-58). Abingdon: Routledge.

Chaurasia, R., \& Bhikajee, M. (2016). Adding entrepreneurship to India's science, technology and innovation policy. Journal of Technology Management and Innovation, 11(2), 86-103. http://dx.doi. org/10.4067/S0718-27242016000200009

Chrispino, A. (2016). Introdução ao estudo das políticas públicas: uma visão interdisciplinar e contextualizada. Rio de Janeiro: FGV.

Evans, P. B. (1995). Embedded Autonomy: states and industrial transformation. New Jersey: Princeton University Press.

Evans, P. B. (2010). Constructing the 21st century developmental state: potentialities and pitfalls. In Edigheji, O. (Ed.), Constructing a democratic developmental state in South Africa: potentials and challenges (pp. 37-58). Cape Town: HSRC Press.

Evans, P. B. (2011). The capability enhancing developmental state: concepts and national trajectories. [Discussion Text n. 63]. Centro de Estudos sobre Desigualdade e Desenvolvimento (CEDE). Niterói: UFF.

${ }^{6}$ To see the SIBRATEC-ET cases in Santa Catarina, Paraná and Minas Gerais, Retrieved from https://www.dropbox.com/sh/40axojcm5dknebc/AABcVdS3pW274ZMZ6sklTyn5a?dl=0 
Fiani, R. (2011). Cooperação e conflito: instituições e desenvolvimento econômico. Rio de Janeiro: Elsevier.

Gerschenkron, A. (1962). Economic backwardness in historical perspective. In Granovetter, M. \& Swedberg, R., The sociology of economic life (pp. 5-30). Westview Press.

Gomide, A. A., \& Pires, R. R. C. (2014). Capacidades estatais e democracia: a abordagem dos arranjos institucionais para a análise de políticas públicas. In Gomide, A. A. \& Pires, R. R. C. (Eds.). Capacidades estatais e democracia: arranjos institucionais e políticas públicas (pp. 15-28). Brasília: IPEA.

Hodgson, G. M. (1988). Economics and institutions: a manifesto for modern institutional economics. Philadelphia: University of Pennsylvania Press.

Instituto Brasileiro de Geografia e Estatística (IBGE). (2014). Classificação Nacional de Atividades Econômicas (CNAE). Retrieved from https://cnae.ibge.gov.br/?view=estrutura

Instituto Nacional de Tecnologia (INT). (2016). Implantação da Rede de Extensão Tecnológica do Rio de Janeiro para apoio às micro, pequenas e médias empresas. [Relatório Técnico-Gerencial Final]. Rio de Janeiro: INT.

Kuznets, S. S. (1973). Modern economic growth: findings and reflections. American Economic Review, 63(3), 247-258.

Langlois, R. N. (1986). The new institutional economics: an introductory essay. In Langlois, R. N. (Ed.), Economics as a process: essays in the new institutional economics (pp.1-25). Cambridge University Press: Cambridge.

Madeira, P. (2009). Extensão industrial em sistemas locais de produção: os efeitos da aglomeração na aquisição e difusão de novas capacitações em PME. Dissertação (Mestrado em Engenharia de Produção) - Escola Politécnica, Universidade de São Paulo (USP), São Paulo, Brasil.

Mazzucato, M. (2011). The entrepreneurial state. London: Demos.

Mendes, H. S. (2016). Extensão tecnológica no Brasil: uma análise da oferta e da demanda das empresas de metalmecânica da zona oeste do município do Rio de Janeiro. Tese (Doutorado em Políticas Públicas, Estratégias e Desenvolvimento) - Instituto de Economia, Universidade Federal do Rio de Janeiro (UFRJ), Rio de Janeiro, Brasil.

Mendes, H. S., \& Hasenclever, L. (2015). Development, entrepreneurial activity and industrial extension. In Rovere, R. L. L., Ozório, L. M. \& Melo, L. J. (Orgs.), Entrepreneurship in BRICS: policy and research to support entrepreneurs (pp. 239-253). Cham: Springer International Publishing.

Mendes, H. S., Ferreira, M. L. A., Hasenclever, L., \& Teixeira, C. A. M. (2017). Extensão tecnológica e desenvolvimento regional: o caso Sibratec-ET Rede RJ (2017). Blucher Engineering Proceedings. http:// dx.doi:10.5151/enei2017-44.
Ministério da Ciência, Tecnologia e Inovação (MCTI). (2013a). Ações de C,T\&I - Sistema Brasileiro de Tecnologia (SIBRATEC). [Relatório Técnico]. Brasília: MCTI.

Ministério da Ciência, Tecnologia e Inovação (MCTI). (2013b). Secretaria de Desenvolvimento Tecnológico e Inovação. Programa SIBRATEC 2013. [Relatório de Gestão]. Brasília: MCTI.

Nogueira, M. O. (2017). Um pirilampo no porão: um pouco de luz nos dilemas da produtividade das pequenas empresas e da informalidade no Brasil. Brasília: IPEA.

North, D. C. (1990). Institutions, institutional change and economic performance. Cambridge: Cambridge University Press.

Organisation for Economic Co-operation and Development (OECD). (1997). Small businesses, job creation and growth: facts, obstacles and best practices [Best Practices]. Paris: OECD.

Rovere, R. L. L., Hasenclever, L. \& Pinto, J. P. de M. (2014). An introduction to small and medium-sized enterprises (SMEs) in Brazil. In Hernandez, N. \& Ramirez, J. (Orgs.), MEs unleashing the potential: opportunities and challenges? The cases of Brazil, Mexico, France, Germany, Italy and Spain (pp. 16-41). New Delhi, Índia: Bloomsbury.

Rutherford, M. (1994). Institutions in economics: the old and the new institutionalism. Cambridge University Press, Cambridge.

Rutherford, M. (2001). Institutional Economics: then and now. Journal of Economic Perspectives, 15(3), 173-194. http://dx.doi:10.1257/ jep.15.3.173.

Salami, R., \& Soltanzadeh, J. (2012). Comparative analysis for Science, Technology and Innovation Policy: lessons learned from some selected countries (Brazil, India, China, South Korea and South Africa) for other LDCs like Iran. Journal of Technology Management and Innovation, 7(1), 211-227. http://dx.doi:10.4067/ S0718-27242012000100014.

Schumpeter, J. A. [1934] (1961). The theory of economic development: an inquiry into profits, capital, credit, interest and the business cycle. Oxford: Oxford U.P.

Schumpeter, J. A. [1943] (1976). Capitalism, socialism e democracy. London: George Allen \& Unwin (Publishers).

United Nations Conference on Trade and Development (UNCTAD). (2016). Structural transformation for inclusive and sustained growth. [Trade and Development Report]. New York and Geneva: United Nations.

Yin, R. K. (2014). Case study research: design and methods. Fifth edition. Thousand Oaks, CA: Sage Publications. 
